\title{
CARDIOVASCULAR RESPONSE TO ACUTE COLD STRESS IN NON-OBESE AND OBESE HEALTHY ADULTS
}

\author{
Grewal $\mathrm{S}^{1}$, Sekhon $\mathrm{TS}^{2}$, Walia L ${ }^{1}$, Gambhir $\mathrm{RS}^{3}$
}

ABSTRACT

BACKGROUND: Obesity is a global epidemic with important health care and financial implications. The cold pressor test (CPT) which is considered to be a sympathy-excitatory manoeuvre is a simple, noninvasive and validated test. The objective of this study was to assess and compare the cardiovascular response to cold pressor test in non-obese and obese healthy adults.

METHODS: The study included 400 subjects, of which the study group included 200 adults who had body mass index (BMI) of more than $30 \mathrm{Kg} / \mathrm{m},{ }^{2}$ and 200 non-obese adults were enrolled as controls with BMI less than $25 \mathrm{~kg} / \mathrm{m}^{2}$. The study was conducted for a period of two months. CPT was used to assess cardiac response to acute cold exposure in the present study. Baseline systolic and diastolic blood pressure recording was done using mercury sphygmomanometer during resting condition and following cold pressor test. The results were expressed as mean, standard deviation, and data were analyzed using ANOVA test. $P<0.05$ was considered statistically significant.

RESULTS: The mean change in systolic blood pressure before and after cold pressor test (CPT) was less in obese $(7.12 \pm 5.28)$ as compared to non-obese subjects $(10.38 \pm 6.35)$. This was statistically significant which indicates impaired sympathetic function in otherwise healthy obese.

CONCLUSION: The study concluded that blood pressure response to cold pressor test was reduced in obese compared to non-obese subjects indicating reduced sympathetic activity in healthy obese adults.

KEYWORDS: cold pressor test, systolic blood pressure, diastolic blood pressure, body mass index

\section{DOI: http://dx.doi.org/10.4314/ejhs.v25i1.7}

\section{INTRODUCTION}

Obesity is one of the common and significant health hazards. It is a medical condition in which excess body fat accumulates to the extent that it may have an adverse effect on health, leading to reduced life expectancy and/or increased health problems (1). Obesity is a result of chronic imbalance between energy intake and energy expenditure. Energy balance is regulated by various neural and hormonal mechanisms. Obesity is a global epidemic characterized by hemodynamic and metabolic alterations. Obesity is implicated in pathogenesis of various diseases particularly cardiovascular diseases, diabetes mellitus type 2 and certain types of cancer (1). Obesity is measured by body mass index (BMI), a measure based on individual's weight and height. Based on unequivocal data of morbidity; BMI $\geq$ 30 is most commonly counted as threshold for obesity (2). It has been reported that both central and peripheral nervous systems are involved in development of obesity and also in its various cardiovascular, metabolic and respiratory physiology complications (3). Several studies in literature suggest that the autonomic nervous system of obese individuals is chronically altered $(4,5)$. Since autonomic nervous system is

\footnotetext{
${ }^{1}$ MM Medical College and Hospital, Solan, India

${ }^{2}$ SKSS Dental College and Hospital, Ludhiana, India

${ }^{3}$ Gian Sagar Dental College and Hospital, India

Corresponding Author: Ramandeep Singh Gambhir, Email: raman1g@yahoo.co.in
} 
involved in the energy balance and regulation of cardiovascular system, alteration in autonomic nervous can been strongly implicated in the development of obesity and pathophysiology of various cardiac complications (6).

Among the different non-invasive techniques available for assessing the autonomic cardiovascular status, the cold pressor test is considered to be a sympatho-excitatory manoeuvre (7). It is a simple, non- invasive and validated test of sympathetic activation. The cold pressor test in healthy subjects triggers a vascular sympathetic activation and an increase in blood pressure. Hence, the blood pressure responses to environmental stressors as acute exposure to cold could be used as indicators of global sympathetic activation, and thus of cardiac status (8). Studies suggest that obesity is associated with sympathetic imbalance which is implicated in both development of obesity and various cardiovascular complications $(9,10)$. Sympathetic nervous system is a determinant of energy balance, and its underactivity contributes to weight gain, while in contrast, sympathetic over-activity predisposes to development of obesity related cardiovascular complications. Previous studies provided evidence that reduction in sympathetic activity is associated with weight gain (11). There is also evidence that obesity-associated sympathetic activation represents potential mechanism contributing to increased cardiovascular complications in obesity (12). Hence, this study was undertaken to assess the cardiovascular response to cold pressor test (CPT) in non- obese and obese healthy adults.

\section{METHODS AND MATERIALS}

Ethical clearance: The study was conducted in the Department of Physiology, Dayanand Medical College and Hospital, Ludhiana, India. It was conducted over a two month period. The study protocol was approved by the Institutional Review Board of Dayanand Medical College and Hospital. Informed consent was obtained from each subject before the beginning of the study.

\section{Study Sample and sampling technique}

This study was a cross-sectional comparative study. Four hundred subjects (male and female) aged more than 25 years were divided into an obese group $(n=200)$ and lean group $(n=200)$ based on BMI. Subjects who volunteered to participate and met the inclusion criteria were included in the study. Sample size was calculated using the formula $\mathrm{n}=4\left(\mathrm{pq} / \mathrm{L}^{2}\right)$ where $\mathrm{p}=$ population proportion of positive character, $q=1-p$ and $\mathrm{L}=$ Allowable Error. For this study, L was presumed to be $10 \%$ of $p$ giving a power of (1-L) i.e. $90 \%$ to study. $p$ was taken as $30 \%$, the minimum known overall of obesity under consideration. After calculation of the study sample using a statistical software, the final sample size was calculated to be 424. After exclusion of drop-outs, 400 subjects were finally recruited for the study which were equally categorized into healthy obese and non-obese subjects.

Various parameters employed: Study participants were selected on the basis Anthropometric parameters in which height (meters) and weight $(\mathrm{kg})$ were noted for each subject. Height was measured using a standard stadiometer with the subjects standing in erect posture. The readings were taken to the nearest 0.1 $\mathrm{cm}$. Weight was measured using calibrated weighing machine. These data were used to calculate Body Mass Index of each subject. Subjects were divided in obese and non-obese groups depending on the BMI given by World Health Examination (WHO) classification (13). The study group included those who had a BMI $>30 \mathrm{~kg} / \mathrm{m}^{2}$ (Obese), and the control group included those with a BMI $<25 \mathrm{~kg} / \mathrm{m}^{2}$ (non-obese).

Table 1: WHO Classification of BMI

\begin{tabular}{cc}
\hline BMI & Classification \\
\hline$<\mathbf{1 8 . 5}$ & Underweight \\
$\mathbf{1 8 . 5 t o 2 4 . 9}$ & Normal \\
25to29.9 & Overweight \\
30to39.9 & Obese
\end{tabular}

Inclusion criteria and general examination: Subjects who aged 25 years and older were included in the study. The detailed relevant clinical history was obtained from the subjects. This was followed by a brief general and physical examination. Healthy subjects who could follow instructions and who were non-smokers and nonalcoholics were included in the study. Those subjects with history of any respiratory, cardiovascular and neurological disorders, in 
addition to being incapable of performing a cold pressor test, were excluded from the study. Patients with abnormal random blood sugar (tested with glucometer) were also excluded from the study. Details of proceedings and need of history was described to each volunteer so that each subject was in a state of calmness and free from anxiety at the time of the test.

Cold Pressor Test (CPT): The cold pressor test was performed according to Hine's protocol. After the nature of the test was explained, each participant was asked in a supine position in a quiet room. A resting blood pressure reading was noted at the start of the study. For the purpose of this study, a blood pressure level of less than 140/90 mm $\mathrm{Hg}$ was taken as normotension. The subjects were then asked to immerse their hand in cold water $\left(4-6{ }^{\circ} \mathrm{C}\right)$ upto wrist for 2 minutes. During the period of ice-immersion, the blood pressure readings were taken in the opposite arm at 20 second interval; the highest of these readings was designated as peak blood pressure. The difference between the peak and basal blood pressures determined the level of vascular activity. Maximum increase in systolic and diastolic pressures during cold pressor test was calculated and recorded.

Statistical analysis: Data were cleaned, entered into computer and analyzed using SPSS Windows Version 16. Descriptive analysis was done using frequencies and percentages.The results were expressed in mean + S.D., and were compared with the control group. The data was analyzed using ANOVA test. P-values of $<0.05$ were considered statistically significant.

\section{RESULTS}

Mean age of study subjects in the control group and study group was $34.8 \pm 10.24$ and $33.38 \pm 8.73$ years respectively. Table 2 depicts the anthropometric variables of study (obese) and control group (non-obese). The mean BMI of the study group was $34.25 \pm 3.13 \mathrm{~kg} / \mathrm{m}^{2}$, and that of control group was $23.78 \pm 2.06 \mathrm{~kg} / \mathrm{m}^{2}$ with age and sex matched in both the groups.

Table 2: Variables of study (obese) \& control group (non-obese)

\begin{tabular}{llcc}
\hline \multicolumn{2}{c}{ Variable } & Control group & Study group \\
\hline Age $(\mathrm{yrs})$ & & $34.86 \pm 10.24$ & $33.38 \pm 8.73$ \\
$\mathrm{Sex}$ & Male & $72(36 \%)$ & $56(28 \%)$ \\
& Female & $128(64 \%)$ & $144(72 \%)$ \\
\multicolumn{2}{c}{$\mathrm{BMI}\left(\mathrm{kg} / \mathrm{m}^{2}\right)$} & $23.78 \pm 2.06$ & $34.25 \pm 3.13$ \\
\hline
\end{tabular}

Comparisons of change in mean systolic and diastolic blood pressure in response to CPT in the control and study group are indicated in Table 3. The difference in mean systolic blood pressure (SBP) recorded before and after cold pressor test was low in the study group (Obese) $(7.12 \pm 5.28$ $\mathrm{mmHg}$ ), as compared to the control group (10.38 $\pm 6.35 \mathrm{mmHg}$ ), and the difference was statistically significant. $(\mathrm{p}=0.006)$. The difference in mean diastolic blood pressure (DBP) recorded before and after CPT was lower in the study group (7.32 $\pm 3.95 \mathrm{mmHg}$ ) as compared to the control group $(7.84 \pm 3.72 \mathrm{mmHg}$ ), but the difference was not statistically significant. $(\mathrm{p}=0.500)$. Figure 1 indicates that there was reduced rise in mean SBP on CPT in the study group $(7.12+5.28 \mathrm{~mm}$ of $\mathrm{Hg})$ as compared to the control group $(10.38+$ $6.35 \mathrm{~mm}$ of $\mathrm{Hg}$ ). Figure 2 indicates that there was a decrease DBP change in response to CPT in the study group $(7.32+3.95 \mathrm{~mm}$ of $\mathrm{Hg})$ as compared to control group $(7.84+3.72 \mathrm{~mm}$ of $\mathrm{Hg})$. 
Table 3: Effect of BMI on systolic and diastolic blood pressure during Cold-Pressor test

\begin{tabular}{|c|c|c|c|}
\hline Variable & Control group & Study group & P \\
\hline Mean SBP change during CPT in $\mathrm{mm} \mathrm{Hg}$ & $10.38 \pm 6.35$ & $7.12 \pm 5.28$ & $0.006 *$ \\
\hline Mean DBP change during CPT in $\mathrm{mm} \mathrm{Hg}$ & $7.84 \pm 3.72$ & $7.32 \pm 3.95$ & 0.5 \\
\hline
\end{tabular}

$*$ = Significant

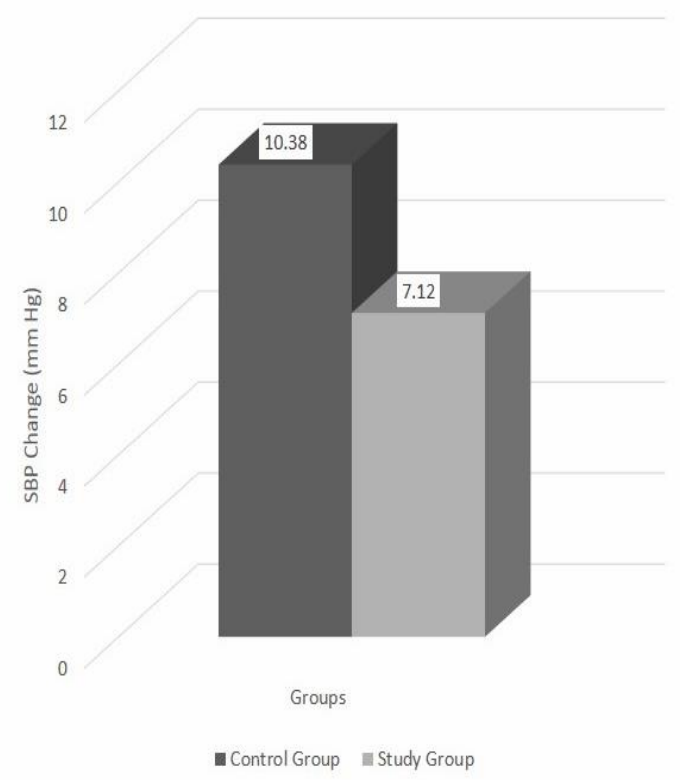

Fig 1: Systolic blood pressure (SBP) change in response to $\mathrm{CPT}$ in both the groups

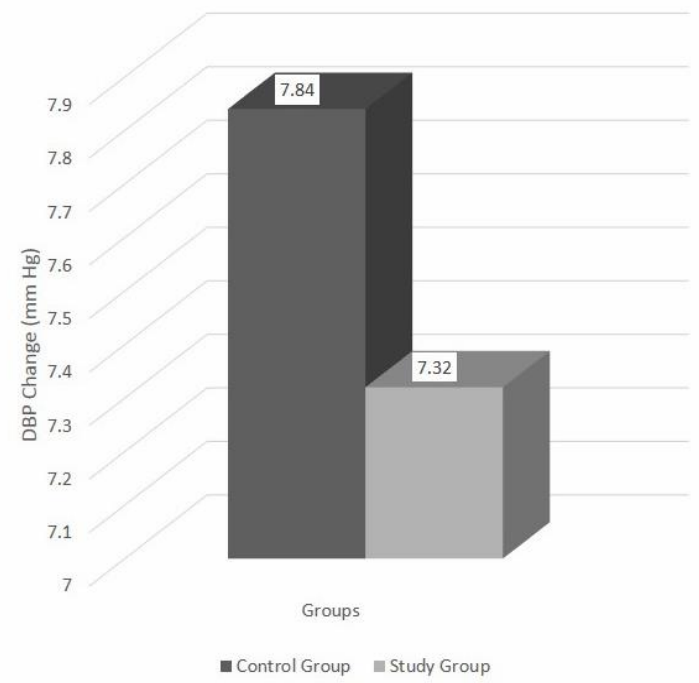

Fig 2: Diastolic blood pressure (DBP) change in response to $\mathrm{CPT}$ in both the groups

\section{DISCUSSION}

In the present study, the cardiovascular response to cold pressor test was assessed and compared in non-obese and obese healthy adults. The study indicated that the systolic and diastolic BP responses were reduced in obese subjects when compared to the non-obese subjects on exposure to acute cold. The impaired CPT in the control group (obese) could possibly be because of hypofunctional sympathetic nervous system in obesity. The results of the study correlate with observations made by other authors $(14,15)$.

The cold pressor test, a provocative test developed by Hines, is considered to be a potentially useful indicator of future hypertension (16). Cold pressor test is often used to evaluate the sympathetic influence on circulation in humans. It is a well-known fact that the cold pressor test provokes a remarkable increase in sympathetic activity in healthy humans, and is an indicator of vasoconstrictor tone (17). The CPT pressor response is mediated by central command and local metabolites, particularly adenosine (18). Obesity impairs autonomic control of heart rate and blood pressure. The results of the study showed a reduction in the blood pressure responses among the obese on exposure to cold. The afferent fibres for this response are pain fibres stimulated on exposure to cold, and efferent fibres are sympathetic fibres. Hence, lesser increase in blood pressure response to CPT points to sympathetic insufficiency in obese adults.

The results of this study are in accordance with observations made by other authors, who also suggest blunted sympathetic response in obese adults $(19,20)$. This reduced sympathetic response in established obesity may be responsible for the maintenance of obese state (21). The decrease in sympathetic activity may result in a disordered homeostatic mechanism, thus promoting excessive storage of energy (22). 
Sympathetic nervous system is a determinant of energy expenditure. It has been indicated that individuals with low resting muscle sympathetic nerve activity may be at risk for body weight gain resulting from a lower metabolic rate (23). Sympathetic underactivity may contribute to deficient thermogenesis, positive energy balance and weight gain (24). Moreover, experimental evidences have demonstrated that an increase in sympathetic and thermogenic activity reduces food intake $(25,26)$. Therefore, the obesity can be due to an increase in food intake associated with a reduced activity of the sympathetic nervous system and thermogenesis.

Obesity can also result from impaired sympathetic nervous activity and low activity of adrenal medulla (27). It has been suggested by a study that, with weight gain, there is a decrease in sympathetic activity and reduction in baroreflex functioning because of central sympatho inhibition (28). Obese individuals manifest lower sympathetic nervous system activity against physiological perturbations as cold exposure and food intake. Weight loss following low calorie diet can cause improvement in autonomic function as is demonstrated by a study in which there was improvement in blood pressure to stress test as cold pressor test (29).

There were few limitations in the current study. Firstly, we assessed the cardiovascular response to CPT in obese subjects, but we did not analyze its correlation with age and sex groups. This assessment may have allowed us to explain the tendency of older obese subjects to have a blunted sympathetic response to Cold Pressor test. Secondly, we focused on the effect of obesity on cardiovascular response to Cold Pressor test, but we did not analyze the overweight and the underweight group. Thus, future studies could be undertaken for assessment in this regard.

The results of the study show that obesity is associated with reduced sympathetic reactivity to acute cold stress. This reduced sympathetic reactivity in established obesity may be responsible for the maintenance of obese state. Therefore, CPT, being a reliable, non-invasive and simple screening tool in early diagnosis of autonomic cardiac dysfunction, may prove an important aid in identification of those prone to weight gain and are at higher risk of cardiovascular complications.
The findings of our study suggested impaired cardiovascular response on cold pressor test in the obese. Thus, CPT could be employed as a mode of screening for those prone to obesity, allowing for early interventional programmes (lifestyle and dietary modifications) in order to prevent the onset of obesity related cardiovascular sequelae in future.

\section{REFERENCES}

1. Haslam David W, James W Philip T. Obesity. The Lancet, 2005;366:1197-1209.

2. Park K. Obesity. In: Park K, 15th ed. Textbook of Preventive and social Medicine. Jabalpur: Banarsidas Bhanot publishers; 1998;293-294.

3. Bray GA. Medical consequences of obesity. $J$ Clin Endocrinol Metab, 2004;89:2583-9.

4. Valensi P, Thi BN, Lormeau B, Paries J, Attali JR. Cardiac autonomic function in obese patients. Int J Obes Relat Metab Disord, 1995;19:113-8.

5. Arrone LJ, Mackintosh R, Rosenbaum M, Leibel RL, Hirsch J. Cardiac autonomic nervous system activity in obese and neverobese young men. Obes Res, 1997;5:354-9.

6. Bray GA. Autonomic and endocrine factors in the regulation of energy balance. Fed Proc, 1986;45:1404-10.

7. Park J, Middlekauff HR, Campese VM. Abnormal sympathetic reactivity to the cold pressor test in overweight humans. Am J Hypertens, 2012;25:1236-41.

8. Sheila R Pai, Amrutha Mary, Rekha D Kini, Bhagyalakshmi K. Effects of cold pressor test on blood pressure and heart rate variability in wards of hypertensive parents. IJPCBS, 2013; 3:839-42.

9. Webber J, MacdonaldI A. Signalling in bodyweight homeostasis: neuroendocrine efferent signals. Proc Nutr Soc, 2000;59:397-404.

10. Scherrer U, Randin D, Tappy L, Vollenweider $P$, Jequier E,Nicod P. Body fat and sympathetic nerve activity in healthy subjects. Circulation, 1994;89:2634-40.

11. Monda M, Messina G, Vicidomini C, Viggiano C, Mangoni C, De Luca B. Activity of autonomic nervous system is related to body weight in pre menopausal, but not in post menopausal women. Nutritional Neuroscience, 2006;9:141-5. 
12. Shibao C, Gamboa A, Diedrich A, Ertl AC, Chen KY, Byrne DW et al. Autonomic contribution to blood pressure and metabolism in obesity. Hypertension, 2007;49:27-33.

13. World Health Organization. Obesity; preventing and managing the global epidemic. Geneva: WHO 1998.

14. Monteiro G, Chathoth V, Kishan K. Cardiac autonomic response during a cold pressor test in normal and overweight adults. IJBAR, 2012;3:514-6.

15. Rinku G, Varun M, Neera G, Usha D, Yogesh T. A study of autonomic function tests in obese people. Int J Med Res Health Sci, 2013;2:750-5.

16. Hines EA Jr, Brown GE. The cold pressor test for measuring the reactibility of the blood pressure: data concerning 571 normal and hypertensive subjects. Am Heart J, 1936;11:19.

17. Irani FB, Shinde PU, Heena Kauser GH. Evaluation of autonomic functions in obese and Non-obese medical students. Int J Med Sci Public Health, 2014;3(6):717-719.

18. Pasini FL, Capecchi PL, Colafti M, Randisi P, Di Perri T. Systemic adenosine increase during cold pressor test is dependent on sympathetic activation. Clin Exp Pharmacol Physiol, 1999;26:774-778.

19. Lambert EA, Straznicky NE, Lambert GW. A sympathetic view of human obesity. Clin Auton Res, 2013;23:9-14.

20. Straznicky NE, Lambert GW, Masuo K, Dawood T, Eikelis N, Nestel PJ et al. Blunted sympathetic neural response to oral glucose in obese subjects with the insulin-resistant metabolic syndrome. Am $J$ Clin Nutr, 2009;89:27-36.
21. Van Baak MA.The peripheral sympathetic nervous system in human obesity. Obes Rev, 2001;2:3-14.

22. Peterson HR, Rothschild M, Weinberg CR, Fell RD, McLeish KR, Pfeifer MA. Body fat and the activity of the autonomic nervous system. N Engl J Med, 1988;318:1077-83.

23. Spraul M, Ravussin E, Fontvieille AM, Rising $\mathrm{R}$, Larson DE and Anderson EA. Reduced sympathetic nervous activity. A potential mechanism predisposing to body weight gain. J Clinical Invest, 1993;92:1730-5.

24. Negrão CE, Trombetta IC, Batalha LT, Ribeiro MM, Rondon MU, Tinucci $\mathrm{T}$ et al. Muscle metaboreflex control is diminished in normotensive obese women. Am J Physiol Heart Circ Physiol, 2001;281:H469-75.

25. Bray GA. Reciprocal relation of food intake and sympathetic activity: experimental observations and clinical implications. Int $J$ Obes Relat Metab Disord, 2000;24:8-17.

26. Tentolouris N, Liatis S, Katsilambros N. Sympathetic system activity in obesity and metabolic syndrome. Ann N Y Acad Sci, 2006;1083:129-52.

27. Tataranni PA, Young JB, Bogardus C, Ravussin E. A low sympathoadrenal activity is associated with body weight gain and development of central adiposity in Pima Indian men Obes Res, 1997;5:341-7.

28. Laderbach-Hofmann K, Mussgay L, Ruddel H. Autonomic cardiovascular regulation in obesity. J Endocrinol, 2000;164:59-66.

29. Ashida T, Ono C, Sugiyama T. Effects of Short-Term Hypocaloric Diet on SympathoVagal Interaction Assessed by Spectral Analysis of Heart Rate and Blood Pressure Variability during Stress Tests in Obese Hypertensive Patients. Hypertens Res, 2007;30:1199-203. 